\title{
Air Tightness Control of Passenger Car Wheels
}

\author{
Vatroslav Grubisic \\ Zum Stetteritz 1, Reinheim-Georgenhausen, Germany \\ Email: vatro.grubisic@gmx.de
}

How to cite this paper: Grubisic, V. (2017)

Air Tightness Control of Passenger Car Wheels. Engineering, 9, 171-180.

https://doi.org/10.4236/eng.2017.92008

Received: December 23, 2016

Accepted: February 24, 2017

Published: February 27, 2017

Copyright $\odot 2017$ by author and Scientific Research Publishing Inc. This work is licensed under the Creative Commons Attribution International License (CC BY 4.0).

http://creativecommons.org/licenses/by/4.0/

\begin{abstract}
Since the tubeless tires and especially cast alloy wheels are used, the air tightness of wheels is an important factor of the automobiles quality. Based on specification of the car industry that up to $10 \%$ decrease of the prescribed nominal tire pressure during a time of six-month is allowed, the requirements presented in specifications and norms are treated and validated. The practical experience and influences on the wheel tightness control are discussed and the data presented in a report of a wheel manufacturer, concerning the replacements of wheels in service due to air leakage are evaluated. Summarizing the results of analyses, a proposal is made for the testing of the cast aluminum car wheels to meet the requirements for a reliable and economical air tightness control in modern test facilities.
\end{abstract}

\section{Keywords}

Light Alloy Cast Wheels, Air Tightness, Leakage Control, Painting Influence, Practical Experience

\section{Introduction}

Wheels are safety-related components which have paramount importance for vehicle safety and function. Although they are loaded in a complex manner and are highly stressed during operation, a light-weight and a car related individual design is the primary requirement. Taking into account the possible lowest wheel weight and production costs as well as the possibility of a sophisticated design, the light alloy cast wheels are one of the best options especially for the premium class cars.

To prove the wheel durability, standardized tests like "rotating bending test" (for approval of the wheel disc), "rim roll test" (for approval of wheel rim) and "test under service-like loading in the biaxial test facility" (for approval of the entire wheel) are used; to approve the strength of light cast alloy wheels under special event loading, like hitting a curbstone, also the tests under impact load- 
ing must be made [1]-[7]. All these tests including the X-ray inspection of wheels, guarantee the safety requirements for the wheel as a vital vehicle component as required in specification or standards like ISO 3006 and 7141; SAE J328, J2562 and J267; Guidelines of German TÜV and AK Wheels; CNS 7135 [5]; JASO C614 [6]; etc.

Introducing the casting technology for the production of automotive wheels, the air tightness of rims became an important factor concerning their quality assurance. The air tightness of wheel rim is not influencing the car safety but it influences its function and usage disposition. For the product reliability [8] is of importance that a decreased tire inflation pressure influences the car driving performance, the fuel consumption and also the tire wear and should be avoided. The automatic tire pressure control in modern cars will lead to an improvement in this case. The decrease of the tire pressure through wheel rims can be influenced as well by the cracks as by the rim porosity of casting. Before almost 40 years with tubeless tires on steel wheels, the air tightness was a reason for recalls [8]. The problem was caused by the fatigue cracks which occurred in the weld root (position 1 in Figure 1) as the high strength steel was introduced for the rim production, to decrease the rim thickness and the wheel weight. At operational loading the fatigue cracks which started in the weld root propagated through rim thickness leading to an air leakage and decrease of the tire pressure.

Similar problem (and recall actions) occurred also with the wheels from aluminum alloys with large rims and low profile tires for premium class cars as shown in Figure 2 (left figure: cold formed rims and cast disc, right figure: cast one piece wheel).

For the approval of cast aluminum alloy wheels it was important to check the micro-homogeneity of the rim area, not detectable by used X-ray inspection, which can lead to the tire inflation pressure decrease at usage. Based on agreement of car manufacturer for the leak proof, it was settled that a $10 \%$ decrease of the prescribed nominal tire pressure is allowed during a time of six month. To assure this requirement a certain number of wheels were controlled by means of so-called "water bath bubble test" [3] [5] [6] [7] in order to eliminate wheels with leakage. These tests were carried out after the wheel machining but before the final production steps including painting. Because of many disadvantages of
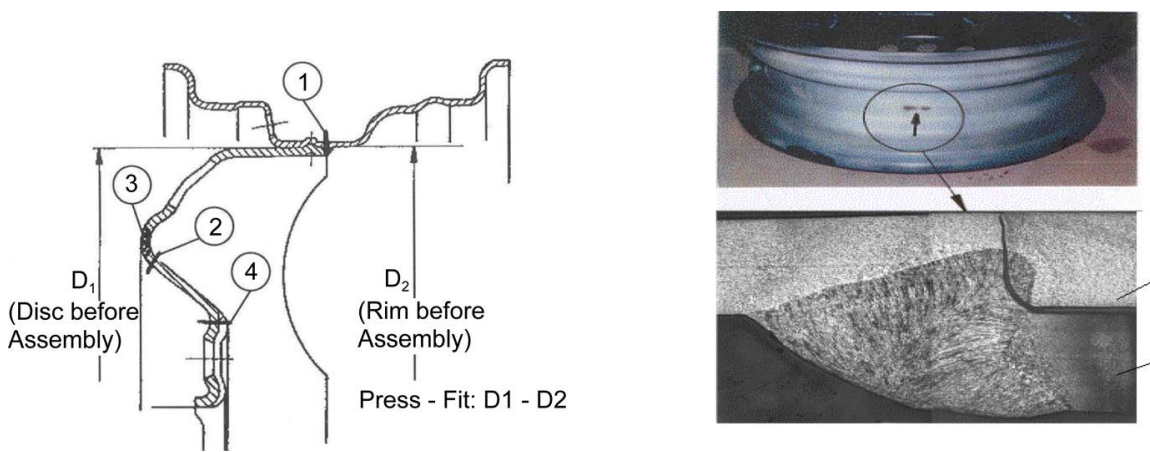

Figure 1. Fatigue cracks on steel wheels in the root of rim/disc weld leading to a tire pressure decrease. 
the "water bath bubble test" (tests not accurate and depend on examiner, not corresponding to the operational conditions, not controlling the total rim leakage, etc.) and the need of the relatively long test time, the procedure using the helium gas was introduced, shown schematically on Figure 3.

For the quality control a permissible leakage rate of $\leq 3.2 \times 10^{-4} \mathrm{mbar} 1 / \mathrm{s}$ was determined, which correspond to the requirement of 0.2 bar pressure decrease at 2 bar tire overpressure ( 3 bar inside the tire and 1 bar outside) and 251 tire volume in a time of 6 month. Thus an integral leak rate as the sum of total leakage is used which allows, assuming corresponding calibrated test facility, a reliable and more accurate quality control of cast wheels than it was the case using the "water bubble test". It must be mentioned that in the case of tires which have a volume of more than $25 \mathrm{l}$, a permissible leakage rate of $\leq 3.2 \times 10^{-4} \mathrm{mbar} 1 / \mathrm{s}$ will correspond to a tire air pressure decrease of $10 \%$ in a time longer than 6 month (e.g. for a tire with a volume of 351 to a time of about 8.4 months or for allowable $10 \%$ decrease in 6 month the allowable leakage rate will be $4.5 \times 10^{-4} \mathrm{mbar}$ $1 / \mathrm{s})$.

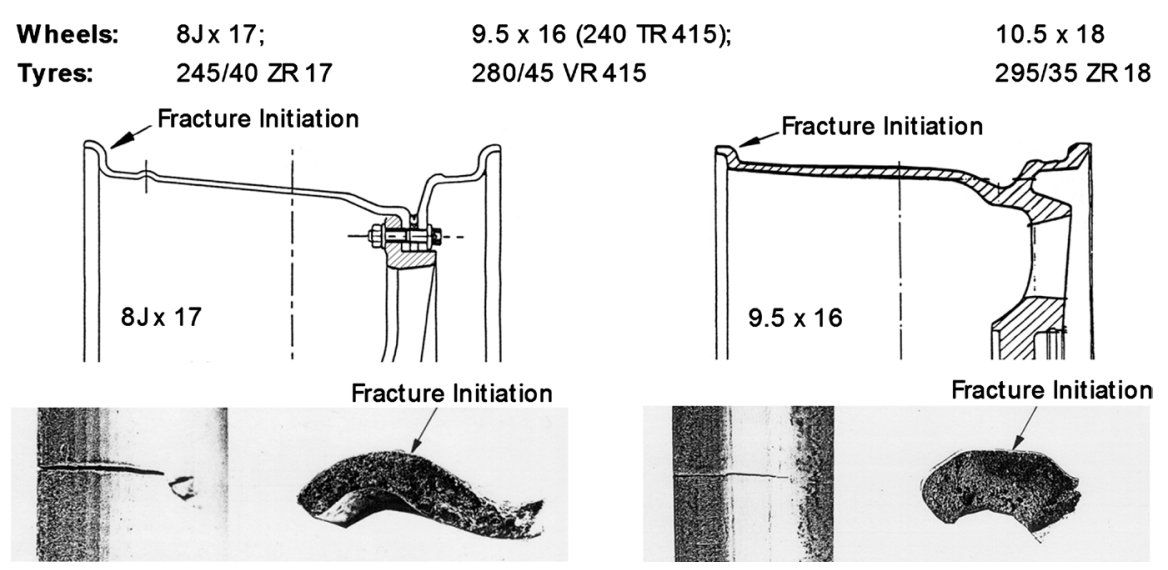

Figure 2. Fatigue cracks on wheels with large rims ( $>7$ inches) and low profile tires at operational usage $(60.000-100.000 \mathrm{~km})$ leading to a tire pressure decrease.

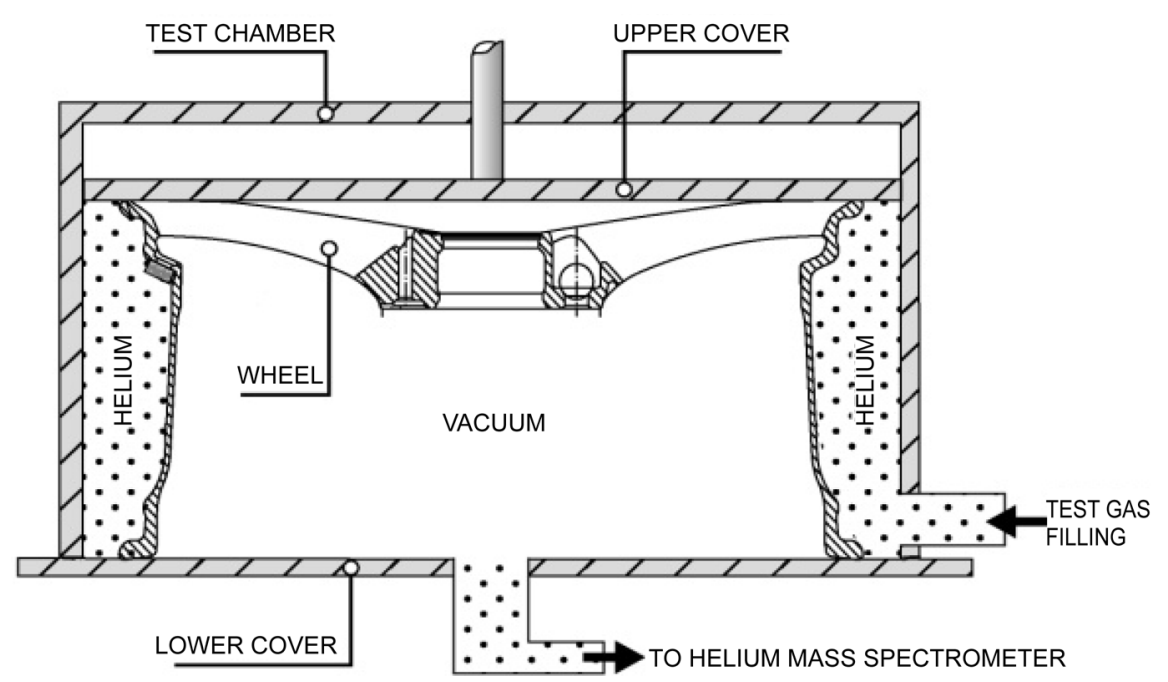

Figure 3. Schematic layout of wheel leakage control with test gas helium. 
Requirements for the air tightness control, described in specific topics of individual car companies specifications and norms [4] [9] [10] [11] [12] [13], correspond basically to the allowable decrease of tire inflation pressure $\leq 0.2$ bar in six month at a tire overpressure $\Delta \mathrm{p}=2$ bar. In specifications of companies, Ref. [4] [9] [10] [11] [12], is prescribed as permissible value a leakage rate of $\leq 3.2 \times$ $10^{-4} \mathrm{mbar} 1 / \mathrm{s}$. In most of specifications the approval must be carried out on unpainted wheels; in specifications [9] [11] [12] is allowed that, in agreement between wheel manufacturer and car company, a leakage test can be made on wheels after painting and description in [13] leads to the assumption that the leakage control should be carried out on painted wheels as finished product.

Concluding this chapter it can be said that most of car companies, based on the test procedures in water bath used almost more than 40 years ago, as the usage of cast light alloy wheels in the car industry was introduced, require in their specifications or company norms that the air tightness is controlled on unpainted wheels. Meanwhile manufacturing of these wheels is significantly improved, from casting technology, painting procedure, used materials and corresponding control (X-ray radioscopy of all wheels, geometrical control, durability control under operational loading, validation under impact loading simulating dynamic, accident like loads at special event in service, etc.) and the air tightness must be carried on $100 \%$ wheels at highly increased production. To prove the influence on air tightness control before or after the painting different investigation were carried out. The scope of these investigations was to prove what would be a most economical, reliable procedure to control the air tightness of cast wheels as their production was increased in individual companies to several millions of wheels pro year.

\section{Influences on Leakage Control}

Based on specific conditions at testing the rim leakage by helium gas and the requirements for quality control on finished product, the question arisen, should the control be made as required in individual specifications before painting or after the wheels are finally manufactured including painting?

To respond this question different investigation were carried out. Their results will be treated in following chapters.

\subsection{Influence of Painting on Results of Air Tightness Control}

To analyse the influences on the accuracy and reliability of the testing on unpainted and painted wheels a specific measurements program was carried out [14]. In this program 25 wheels for Audi (size $7.5 \times 17$ ), were controlled using a helium gas test facility. The measurement program included following steps:

a) Measurement of leakage rate on 25 wheels after machining but before painting.

b) Measurement of leakage rate on the wheel with highest leakage and on the wheel with lowest leakage repeating the measurement 25 times.

c) Measurement of leakage rate on same 25 wheels after painting. 
d) Measuremnt of leakage rate on the wheels under point b. after they were painted repeating measurement 25 times.

The results of the measurements under point a. and $d$. are presented graphically in Figure 4 and corresponding results of the statistical analyses in Figure 5. In Figure 6 and Figure 7 the results of measurements under points b. and c. are presented.

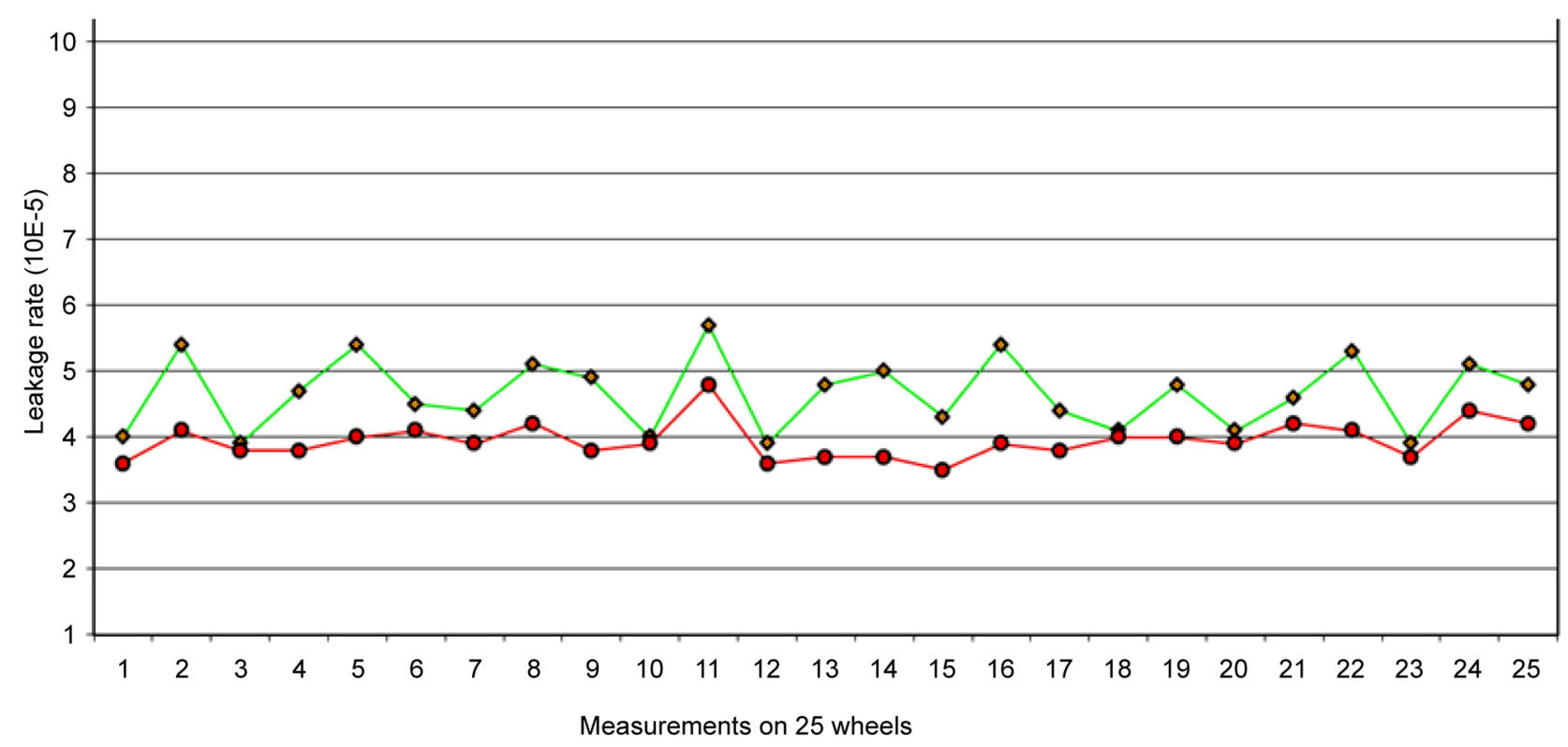

Figure 4. Results of measurements before painting (green $\bullet$ ) and after painting (red $\bullet$ ).

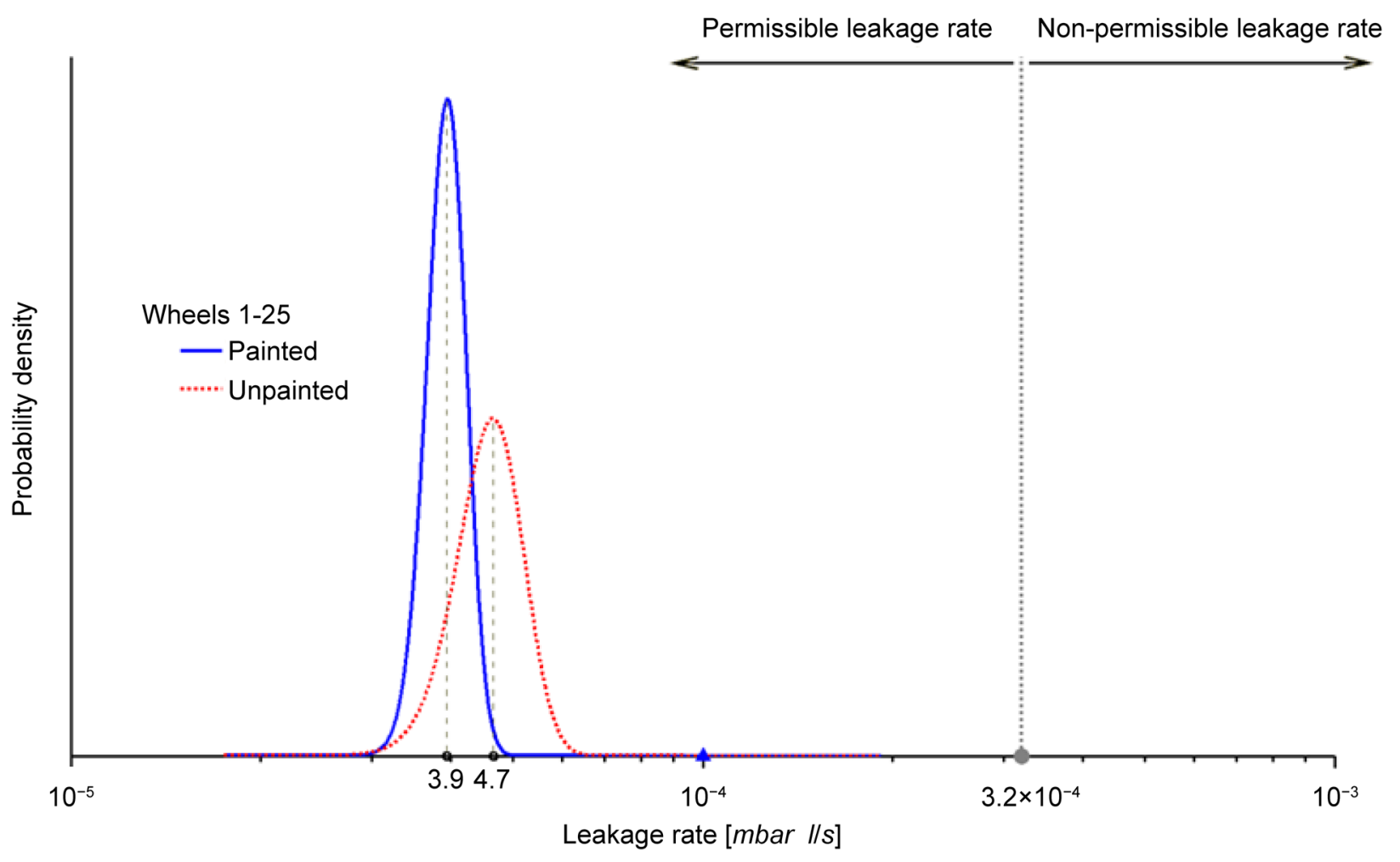

Figure 5. Analysis of 25 wheels non-painted and painted. 


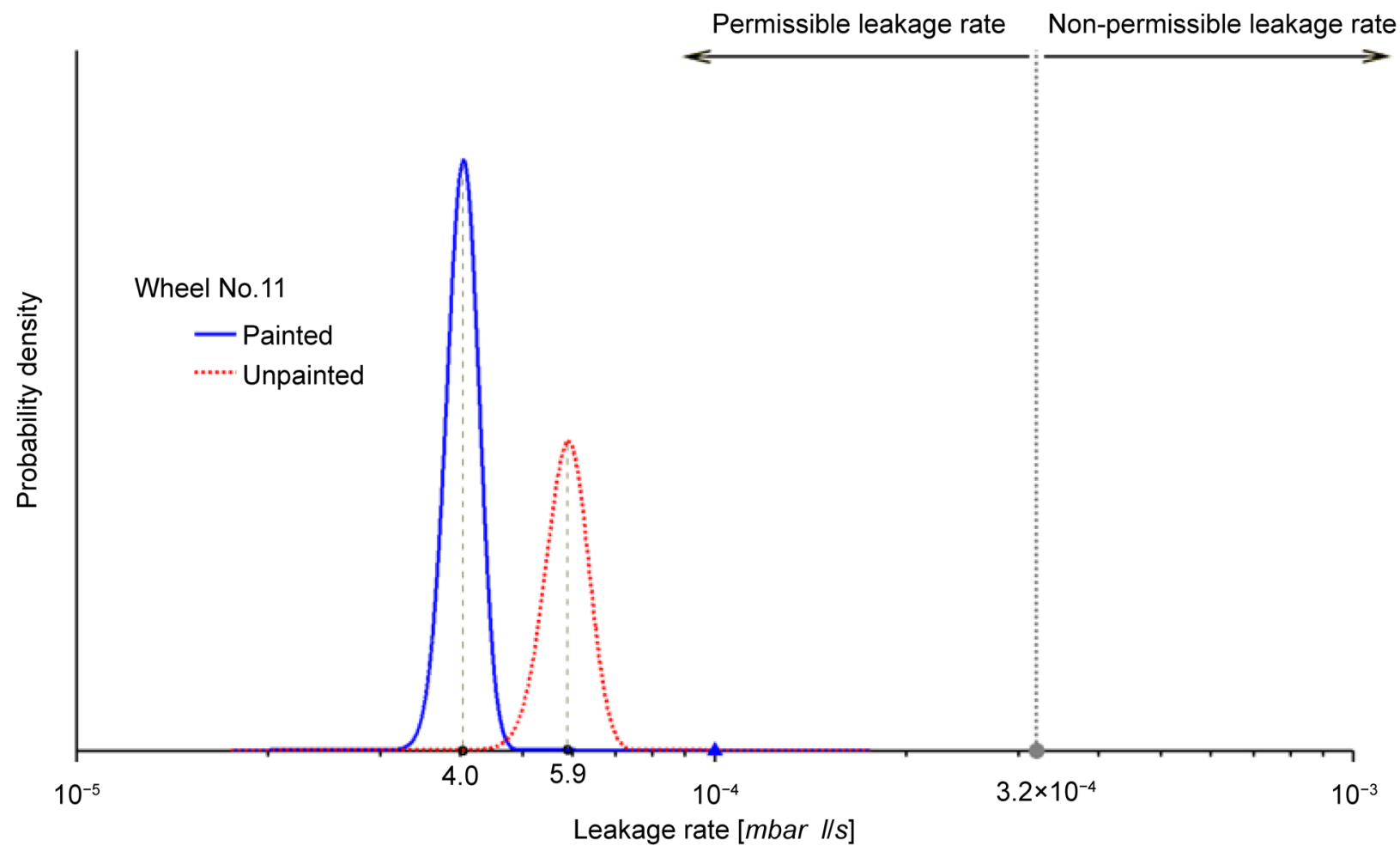

Figure 6. Analysis of wheel 11.

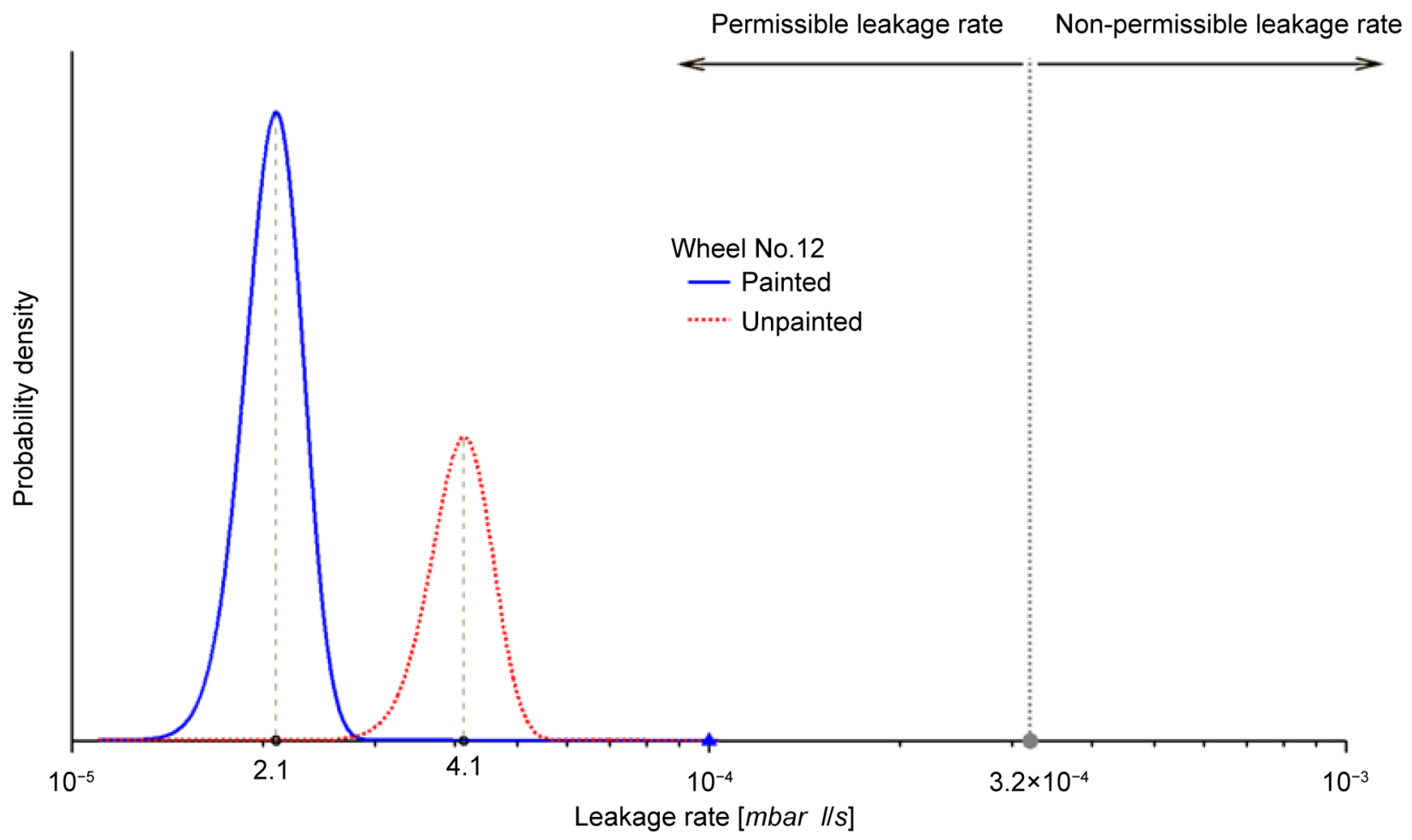

Figure 7. Analysis of wheel 12.

From the measurements presented in Figure 4 can be seen that the difference between measured values is higher for the unpainted wheels than in the case of 
painted wheels. This can be seen better after the results are statistically evaluated and shown in Figure 5. From the Figure 5 can be seen that the mean value (MW) of the leakage rate on unpainted wheels (measuring program a.) is higher than on painted wheels (measuring program c.) with a mean value $\mathrm{MW}=4.7 \times$ $10^{-5}$ in relation to $\mathrm{MW}=3.9 \times 10^{-5}$, but the scatter of measured values is higher on unpainted wheels $(s=0.54)$ compared with painted $(s=0.28)$.

Similar results were determined with the wheel with highest leakage rate (wheel 11, Figure 6) and lowest leakage rate (wheel 12, Figure 7).

On wheel 11. the result of measurements for unpainted state have a mean value $\mathrm{MW}=5.9 \times 10^{-5}(\mathrm{~s}=0.44)$ and for painted state $\mathrm{MW}=4.0 \times 10^{-5}(\mathrm{~s}=$ $0.23)$ as shown in Figure 6.

On wheel 12 the mesured values in case of unpainted state are MW $=4.1 \times$ $10^{-5}$ and scatter $\mathrm{s}=0.44$ and for painted state $\mathrm{MW}=2.1 \times 10^{-5}$ with a scatter of $\mathrm{s}$ $=0.21$.

A generalized evaluation of these analyses show that with unpainted wheels the mean value of measured data as their scatter is slightly higher when compared with data of same wheels after they are painted. Obviously the lacquer layer covers and closes the microporosities in the wheel rim leading to a lower leakage and also lower scatter of measured data. That means that individual measurements on painted wheels deliver more reliable results. To take into account the difference between the tests on unpainted and painted wheels at leakage rate validation the allowable leakage rate on painted wheels should be decreased to a value of $\leq 2.0 \times 10^{-4} \mathrm{mbar} 1 / \mathrm{s}$.

\subsection{Behaviour of the Lacquer Layer under Cyclic Deformations}

To prove the behaviour of painting layer under cyclic deformations as occurring on the rim base under operational loading, tests were made in the Fraunhofer Institute for Structural Durability (LBF)-Darmstadt [Report No. 18 8271, Sept. 2003] with specimens fabricated from rims of cast wheels (material AlSi9Mg) before the painting. On these specimens microholes were drilled comparable to the porosities generating the rim leakage. These test specimens were than painted under similar conditions and same lacquer as used for wheels. Finally the tests were made with these specimens in the servohydraulic test machines simulating stresses as they occur on the rim base due to tire inflation pressure and superimposed wheel loads in service. The test specimens were controlled after the tests were finished, proving their leakage under air pressure up to 5 bar in a special test facility, and the state of lacquer layer concerning possible cracks or other damage. The result was that no cracks or damage of the lacquer layer occurred and no measurable air leakage existed.

\subsection{Behaviour of the Lacquer Layer under Operational Loading of Wheels}

To control the most severe situation of wheels which in unpainted condition had been rejected at the "water bubble tests" and additionally controlled and rejected 
at helium gas tests due to the measured leak rate between $1.3 \times 10^{-3}$ and $8.4 \times$ $10^{-4} \mathrm{mbar} 1 / \mathrm{s}$ but after the painting they passed the tests, having the leak rate lower than allowable: $<3.2 \times 10^{-4}[3]$. The tests were carried out with these wheels in the Fraunhofer Institute for Structural Durability (LBF)-Darmstadt[Report No. 13 8452, Oct. 2002] simulating the service usage in the Biaxial Wheel Test Facility ([1] [2] SAE J 2562), shown in Figure 8. In this test facility the wheel with tire mounted is running inside a rotating drum and is loaded biaxially by vertical and lateral servo hydraulic cylinders simulating operational loading of wheels. With the used test loading program a fatigue of wheels is generated corresponding to a severe customer usage of $300.000 \mathrm{~km}$. During the tests, additionally to simulated operational loading, the tires were several times mounted and inflated (about ten times) to take into account possible damage caused by fitting the tires To take influence of corrosion on lacquer layer in service (practically not occurring on the inner side of the wheel rim being of influence on the wheel tightness) one of tested wheels was subjected, prior to durability test, to a salt spray test after DIN 50021.

During these tests the inflation pressure was controlled and no significant decrease was found. After the durability tests were finished, the rim leakage was checked again by helium test procedure without any negative results related to the air tightness (leak rate $<3.2 \times 10^{-4}$ ). These wheels were stored, with tires mounted and inflated, and the air pressure controlled periodically without registering a significant (higher than 10\%) decrease [3].

\section{Data Related to Wheels with the Rim Leakage in Service}

To prove the situation in the practical usage the data presented in the report [15] will be discussed. In this report the data of the product recall detection in the years 2011 until inclusive 2015 are summarized and statistically evaluated. From the presented data it can be seen that in the last five years of a total number of produced 69 million wheels, produced in four plants of the company in Europe and USA, it was necessary to replace 168 wheels (corresponding to a value of $2.44 \mathrm{ppm}$ of delivered wheels) due to the air leakage of rims. The results show
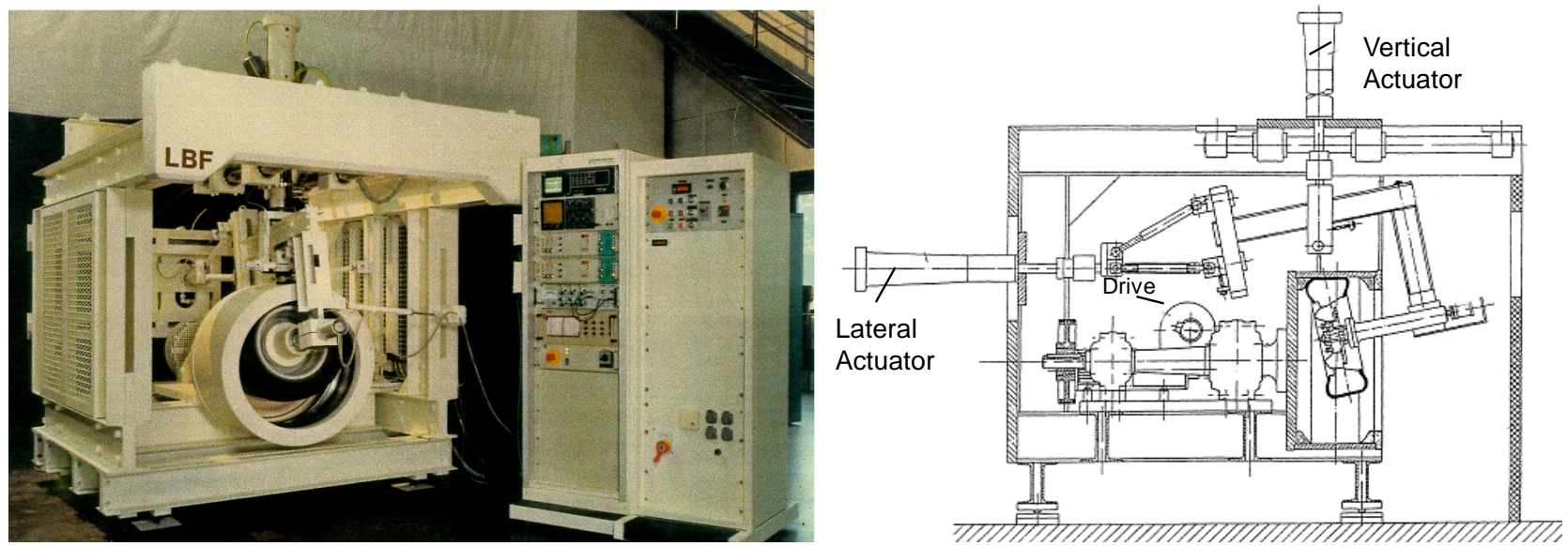

Figure 8. Test Facility for testing of wheels with tires under operational loads. 
also a decrease of the necessary replacements in the years 2014 and 2015, which should be connected with the improved accuracy of the air tightness control in the modern test facilities. Also it can be seen that nevertheless that the amount of tested wheels after the painting in the company was increased, the necessity to replace the wheels due to the rim leakage is decreased influenced by specific improvements in the manufacturing.

\section{Discussion of Results}

The assumption that by painting the leakage rate of wheels will be decreased is correct but it is important that the air tightness of a wheel does not change under operational usage. Otherwise it is found during investigations that the wheels approved in unpainted state (leakage rate lower than allowable) have not satisfied the requirement after painting; this was influenced by manufacturing steps after the leakage test on unpainted wheel, which include chemical and thermical treatment of the wheel up to temperatures of $240^{\circ} \mathrm{C}$, which can generate a change of the microstructure and open some porosities. Based on the results of the presented investigations and taking into account that the air tightness control on painted wheels save costs and time (not necessary to clean the wheel twice, after machining before helium gas testing and again before painting) and decrease the amount of waste due to the cleaning and due to it the ecological impact on environment, the testing of the wheel tightness after painting is better option. Testing of painted wheels as the finished product is fulfilling furthermore better the product liability requirements.

\section{Conclusion}

It will be proposed that for the modern, fully automated and properly calibrated helium gas test facilities, the tests should be carried out on finally manufactured, painted wheels using a permissible leakage rate of $\leq 2.0 \times 10^{-4} \mathrm{mbar} 1 / \mathrm{s}$. To take into account the increased inflation pressure for low profile tires, it is proposed that the leakage approval is based on an overpressure $\Delta \mathrm{p} \geq 2.5$ bar.

\section{References}

[1] Grubisic, V. and Fischer, G. (1983) Automotive Wheels, Method and Procedure for Optimal Design and Testing. SAE Technical Paper No. 830135. https://doi.org/10.4271/830135

[2] Grubisic, V. and Fischer, G. (1984) Procedure for Optimal Lightweight Design and Durability Testing of Wheels. International Journal of Vehicle Design, 5, 659-671.

[3] Anton, W. and Voellmecke, F.-J. (2003) Nachweis der Dichtheit gegossener Aluminiumräder (Leak Proof on Cast Aluminium Wheels). ATZ, 105, 712-716.

[4] Mercedes-Benz, Company Norm (2011) DBL 4912.

[5] Chinese National Standard (1995) CNS 7135, D 2087. Light Alloy Wheels for Automobiles.

[6] Japanese Automobile Standard (2004) JASO C614.

[7] Indonesian National Standards (2008) SNI 1896, Tire Rims for Category M, N and O Motor Vehicles. 
[8] Grubisic, V. (2005) Globalization in Automotive Industry and Product Reliability, Innovative Automotive Technology. Proceedings of IAT Conference and Exposition, Bled, Slovenia, 21-22 April 2005, 1-18.

[9] BMW (2007) Quality Specification. QV 36 026, December 2007.

[10] Volkswagen, A.G. (2005) Gasdichtheits-Prüfung-Leichtmetallräder (Gas-Tightness Control-Light Alloy Wheels). PV 3516.

[11] GM Europe Engineering Standards (2014) Superceded GME10002, Issue No.8.

[12] Ford Functional Specification (2004) 3947a2e, Version 5.

[13] Chrysler Corporation (2003) PS-7138<S>, Change F. Detroit, USA, 4.

[14] BORBET (2015) Report No.: BAT/1762-1, Dichheitsprüfung an unlackierten und lackierten Rädern 7,5X17 für Audi (Air Tightness Control on Painted and Unpainted Wheels 7,5x17 for Audi).

[15] BORBET(2016) Report No.: BAT/1822-1, Ausfallrate der Räder im Betrieb infolge undichter Felgen (Failure Rate in Service due to the Rim Leakage).

Submit or recommend next manuscript to SCIRP and we will provide best service for you:

Accepting pre-submission inquiries through Email, Facebook, LinkedIn, Twitter, etc. A wide selection of journals (inclusive of 9 subjects, more than 200 journals)

Providing 24-hour high-quality service

User-friendly online submission system

Fair and swift peer-review system

Efficient typesetting and proofreading procedure

Display of the result of downloads and visits, as well as the number of cited articles

Maximum dissemination of your research work

Submit your manuscript at: http://papersubmission.scirp.org/

Or contact eng@scirp.org 